\title{
Born Too Soon; Implications in a Tertiary Health Facility in Enugu State Nigeria
}

\section{Nwoga Hope Obiageli ${ }^{1}$, Ajuba Miriam Obinwanne ${ }^{2}$, Igweagu Chukwuma Paulinus ${ }^{3}$}

\author{
${ }^{1}$ Public Health Physician, Department of Community Medicine, Enugu State University Teaching Hospital \\ Enugu, Nigeria \\ ${ }^{2}$ Senior Lecturer and Consultant Public Health Physician, Department of Community Medicine, Enugu State \\ University College of Medicine Enugu and Enugu State University Teaching Hospital Enugu, Nigeria \\ ${ }^{3}$ Lecturer and Consultant Public Health Physician, Department of Community Medicine, Enugu State University \\ College of Medicine Enugu, Nigeria \\ Corresponding Author: Nwoga Hope Obiageli
}

\begin{abstract}
Background: Preterm birth (PTB) is a complex complication of pregnancy with multiple etiologies. This results in long term medical burdens to the families and health care system at large. The objective of the study was to determine the socio-demographic and obstetric characteristics that affect preterm delivery.

Methods: The study was a prospective cohort study conducted at the Obstetrics and Gynecology Department of a tertiary health facility in Nigeria. Data for the study were retrieved from the antenatal and delivery card of the women that delivered at the unit within the time of data collection. Data was analyzed using SPSS version 25 and variables were presented as frequencies, percentages, means, and standard deviation. Bivariate analysis was done using chi-square test. The level of significance was set at $p$ value $\leq 0.05$. Binary logistic regression was used to determine factors that predicted preterm delivery.

Results: Majority of them were married 746(96.9\%), Igbos 763(99.1) and Christians 766(99.5\%). Most of the women were civil servants $429(55.7 \%)$, while about $31.3 \%$ of them were unemployed $241(31.3 \%)$. Majority of the women $484(62.9 \%)$ had tertiary education. About $48 \%$ of them delivered through caesarean section while $53.9 \%$ booked within 14-28weeks gestation.

Delivering through caesarean section and gestational age at booking predicted preterm delivery. Unbooked mothers have about 7times odds of having PTB when compared to those that booked at $\geq 28$ week's gestation.
\end{abstract}

Conclusion: The prevalence of PTB is still high in Nigeria. Booking status of the mother and C/S delivery were found to be strongly associated with preterm delivery.

Key words: Enugu State, Nigeria, Preterm delivery, Prevalence, Tertiary health facility

\section{INTRODUCTION}

Preterm birth (PTB) remains a complex health problem and its complications are considered the leading cause of death among children under five years of age. ${ }^{[1]}$ According to the World Health Organization (WHO), every year an estimated 15 million babies are born preterm ( $<37$ weeks of gestation) and this global trend is rising. Among 184 countries, the rate of preterm birth ranges from $5 \%$ to $18 \%$ of babies born. ${ }^{[2]}$ There is a reported trend of preterm birth rate from 9.8\% (8.3$10.9)$ in 2000 to $10.6 \%(9.0-12.0)$ in 2014. [3] Also majority $(81 \cdot 1 \%)$ of the estimated 14.84 million preterm births in 2014 occurred in Asia and sub-Saharan Africa. ${ }^{[3]}$ PTB is caused by multiple aetiologies as 
there are individual and environmental factors which contributes to it and makes the prediction and prevention of PTB a challenging process during antenatal care. ${ }^{[4]}$

In 2015, the complications of PTB were responsible for approximately 1 million deaths. [1] A variety of factors including demographic and socioeconomic status have been reported to be associated with preterm birth such as maternal age, parity, previous preterm birth, multiple gestation, pregnancy induced hypertension, antepartum hemorrhage, prolonged prelabor rupture of membranes, and urinary tract infections. ${ }^{[5]}$

PTB contributes to about $11 \%$ of annual birth worldwide. ${ }^{[6]}$ It is the leading cause of neonatal morbidity and mortality; and the second most leading cause of underfive death in the world. ${ }^{[7,8]}$ Previous studies have reported risk factors for preterm delivery including extreme maternal age ( $<20$ or $\geq 35$ years), living without partner, living in rural area, stress, heavy physical work, low education level, underweight, overweight and obesity. ${ }^{[7,9]}$ In addition, poor attendance to ANC, antepartum hemorrhage, diabetes, preeclampsia, fetal growth retardation, preterm premature rupture of membranes, multiple pregnancy, and maternal infections have also been associated with an increased risk of preterm delivery. ${ }^{[9-12]}$

PTB remains a complex health problem. Risks for PTB vary according to ethnicity, geography and factors related to lifestyle. ${ }^{[13]}$ Recent studies have shown that preterm complications cause $29 \%$ of neonatal deaths and are responsible for significant morbidity after birth. [14, 15] Prematurity may exert a negative impact on the family sequel to loss of the baby, emotional distress on the family and enormous medical costs associated with the use of different therapeutic resources. As a result of technological advances and improved medical care, many preterm infants survive with less disability. However, these children may remain vulnerable to long-term complications which can last throughout their lifetime. ${ }^{[16]}$

In $75 \%$ of cases, preterm birth is spontaneous and has a multifactorial origin. It appears that risk factors vary according to gestational age, as well as social and environmental aspects. ${ }^{[17]}$

This study aimed to determine the socio-demographic characteristics and obstetric factors associated with preterm delivery among women who delivered at the Obstetrics and Gynecology Department (O\&GD) of a tertiary health facility in Enugu State Nigeria. The study findings are critical in identifying women at risk of PTB, developing prevention and management plans to help reduce the adverse outcomes associated with PTB. The interventions may help to improve newborn' survival rates in our setting.

\section{METHODOLOGY \\ Study area}

The study was carried out at the O\&GD of Enugu State University Teaching Hospital (ESUTH) Park Lane Enugu. ESUTH is one of the tertiary health facilities in Enugu State, Nigeria that provides tertiary services for patients within the state and neighboring States. It also serves as a referral center for both public and private health facilities within and outside the State. It is located within the heart of the State.

\section{Study design}

A Prospective cohort study that lasted for 7 months

\section{Study population}

All the women that delivered at the O\&GD of ESUTH Park Lane Enugu within the time of data collection.

\section{Inclusion criteria}

All the women that delivered at the O\&GD of ESUTH Park Lane Enugu within the time of data collection were included in the study. 


\section{Exclusion criteria}

Women who delivered pre term babies with unknown gestational age

\section{Data collection methods}

Data was collected for a period of 7 months ( $1^{\text {st }}$ July 2020-31 $1^{\text {st }}$ January 2021). Two research assistants $\left(5^{\text {th }}\right.$ year medical students) were used for data collection. Data from the ante-natal and delivery cards were retrieved and entered on a structured pro forma. This was done daily throughout the period of data collection.

\section{Data management \\ Independent variable}

Socio-demographic and obstetric characteristics.

\section{Dependent variables \\ Preterm birth}

\section{Statistical analysis}

All the data were imputed into IBM Statistical Package for Social Sciences (SPSS) version 25 and edited for errors by generating frequencies. Categorical variables were summarized using frequencies and percentages. Chi-squared test was used to test for associations between socio-demographic and obstetric characteristics and preterm birth with significant level placed at $p$-value $\leq 0.05$. Significant variables on bivariate analysis were imputed for multivariate logistic regression. Odds ratio together with their corresponding $\mathrm{p}$ values and confidence intervals were computed.

\section{Ethical considerations}

Ethical clearance for the study was obtained from the Research and Ethics Committee of ESUTH Park lane Enugu. Anonymity was maintained by ensuring that no name reflected on the structured pro forma. Confidentiality was maintained by keeping all the data in a safe.

\section{RESULTS}

Table 1: Socio-demographic and obstetric characteristics of the mothers

\begin{tabular}{|c|c|c|}
\hline Variable & Frequency & Percentage \\
\hline \multicolumn{3}{|l|}{ Age in years } \\
\hline Mean \pm SD & $29.76 \pm 4.69$ & \\
\hline \multicolumn{3}{|l|}{ Age in groups } \\
\hline$\leq 20$ & 14 & 1.8 \\
\hline $21-30$ & 431 & 56.0 \\
\hline $31-40$ & 318 & 41.3 \\
\hline $41-50$ & 7 & 0.9 \\
\hline \multicolumn{3}{|l|}{ Marital status } \\
\hline Married & 746 & 96.9 \\
\hline Single & 24 & 3.1 \\
\hline \multicolumn{3}{|l|}{ Ethnicity } \\
\hline Igbo & 763 & 99.1 \\
\hline Others & 7 & 0.9 \\
\hline \multicolumn{3}{|l|}{ Religion } \\
\hline Christianity & 766 & 99.5 \\
\hline Islam & 4 & 0.5 \\
\hline \multicolumn{3}{|l|}{ Occupation } \\
\hline Civil servants & 429 & 55.7 \\
\hline Agricultural workers & 6 & 0.8 \\
\hline Crafts and related trade workers & 83 & 10.8 \\
\hline Unskilled workers & 11 & 1.4 \\
\hline Unemployed & 241 & 31.3 \\
\hline \multicolumn{3}{|l|}{ Educational level } \\
\hline Tertiary & 484 & 62.9 \\
\hline Secondary completed & 281 & 36.5 \\
\hline Primary completed & 5 & 0.6 \\
\hline \multicolumn{3}{|l|}{ Parity } \\
\hline $1-2$ & 531 & 69.0 \\
\hline $3-4$ & 196 & 25.6 \\
\hline$\geq 5$ & 43 & 5.4 \\
\hline \multicolumn{3}{|l|}{ Anaemia (delivery) } \\
\hline Yes & 303 & 39.4 \\
\hline No & 467 & 60.6 \\
\hline \multicolumn{3}{|l|}{ Caesarean Section } \\
\hline Yes & 368 & 47.8 \\
\hline No & 402 & 52.2 \\
\hline Booking GA in group & $\mathrm{N}=770$ & \\
\hline Un-booked & 146 & 19.0 \\
\hline$\leq 13$ weeks & 61 & 7.9 \\
\hline 14-28 weeks & 415 & 53.9 \\
\hline$\geq 28$ weeks & 148 & 19.2 \\
\hline \multicolumn{3}{|l|}{ GA at delivery } \\
\hline$<37$ weeks & 94 & 12.2 \\
\hline$\geq 37$ weeks & 676 & 87.8 \\
\hline
\end{tabular}

Table 1 shows the sociodemographic and obstetrics characteristics of the mothers. Most of the mothers were aged 21-30years 431(56.0\%). Majority of them were married 746(96.9\%), Igbos 763(99.1) and Christians 766(99.5\%). Most of the women were civil servants $429(55.7 \%)$, while about $31.3 \%$ of them were unemployed 241(31.3\%). Majority of the women $484(62.9 \%)$ had tertiary education. About $48 \%$ of them delivered through caesarean section while $53.9 \%$ booked within 14-28weeks gestation. 
Nwoga Hope Obiageli et.al. Born too soon; implications in a tertiary health facility in Enugu state Nigeria.

Table 2: Factors that affected preterm birth

\begin{tabular}{|c|c|c|c|c|}
\hline \multirow[t]{2}{*}{ Variable } & \multicolumn{2}{|l|}{ Preterm } & \multirow[t]{2}{*}{$\chi^{2}$} & \multirow[t]{2}{*}{ P value } \\
\hline & No $\mathbf{N}(\%)$ & Yes $\mathbf{N}(\%)$ & & \\
\hline \multicolumn{5}{|l|}{ Age in groups } \\
\hline$\leq 20$ & $10(71.4)$ & $4(28.6)$ & 3.631 & 0.304 \\
\hline $21-30$ & $379(87.9)$ & $52(12.1)$ & & \\
\hline $31-40$ & $281(88.4)$ & $37(11.6)$ & & \\
\hline$\geq 41$ & $6(85.7)$ & $1(14.3)$ & & \\
\hline \multicolumn{5}{|l|}{ Marital status } \\
\hline Married & $657(88.1)$ & $89(11.9)$ & 1.720 & 0.190 \\
\hline Single & $19(79.2)$ & $5(20.8)$ & & \\
\hline \multicolumn{5}{|l|}{ Ethnicity } \\
\hline Igbo & $669(87.7)$ & $94(12.3)$ & 0.982 & 0.806 \\
\hline Yoruba & $1(100)$ & $0(0.0)$ & & \\
\hline Hausa & $5(100)$ & $0(0.0)$ & & \\
\hline Others & $1(100)$ & $0(0.0)$ & & \\
\hline \multicolumn{5}{|l|}{ Religion } \\
\hline Christianity & $672(87.8)$ & $94(12.2)$ & 0.700 & 0.705 \\
\hline Islam & $4(100)$ & $0(0.0)$ & & \\
\hline \multicolumn{5}{|l|}{ Occupation } \\
\hline Civil servants & $374(87.2)$ & $55(12.8)$ & 5.003 & 0.287 \\
\hline Agricultural workers & $4(66.7)$ & $2(33.3)$ & & \\
\hline Crafts and related trade workers & $71(85.5)$ & $12(14.5)$ & & \\
\hline Unskilled workers & $9(81.8)$ & $2(18.2)$ & & \\
\hline Unemployed & $218(90.5)$ & $23(9.5)$ & & \\
\hline \multicolumn{5}{|l|}{ Educational level } \\
\hline Tertiary & 434(89.7) & $50(10.3)$ & 4.386 & 0.112 \\
\hline Secondary completed & $238(84.7)$ & $43(15.3)$ & & \\
\hline Primary completed & $4(80.0)$ & $1(20.0)$ & & \\
\hline \multicolumn{5}{|l|}{ Parity } \\
\hline $1-2$ & $464(87.4)$ & $67(12.6)$ & 0.613 & 0.736 \\
\hline $3-4$ & $175(89.3)$ & $21(10.7)$ & & \\
\hline$>4$ & $37(86.0)$ & $6(14.0)$ & & \\
\hline \multicolumn{5}{|l|}{ Anaemia (delivery) } \\
\hline Yes & $261(86.1)$ & 42(13.9) & 1.275 & 0.259 \\
\hline No & $415(88.9)$ & $52(11.1)$ & & \\
\hline \multicolumn{5}{|l|}{ Caesarean Section } \\
\hline Yes & $308(83.7)$ & $60(16.3)$ & 11.037 & $0.001 *$ \\
\hline No & $368(91.5)$ & $34(8.5)$ & & \\
\hline \multicolumn{5}{|l|}{ Booking GA in group } \\
\hline Un-booked & $99(67.8)$ & $47(32.2)$ & 68.560 & $<0.001^{*}$ \\
\hline$\leq 13$ weeks & $59(96.7)$ & $2(3.3)$ & & \\
\hline 14-28 weeks & $380(91.6)$ & $35(8.4)$ & & \\
\hline$\geq 28$ weeks & $138(93.2)$ & $10(6.8)$ & & \\
\hline
\end{tabular}

GA Gestational age * Statistically significant

Table 2 shows factors that affected preterm birth. Delivering through Caesarean section $\left(x^{2}=11.037, \mathrm{p}=0.001\right)$ and gestational age at booking $\left(\chi^{2}=68.560, \mathrm{p}=<0.001\right)$ significantly affected PTB.

Table 3: Predictors of preterm birth

\begin{tabular}{|l|l|l|l|l|}
\hline Variable & Odds ratio & P value & \multicolumn{2}{c|}{$\begin{array}{l}\text { 95\% CI for odds ratio } \\
\text { Lower }\end{array}$} \\
\hline Marital status & & & & \\
\hline Married & 1.1601 & 0.395 & 0.540 & 4.745 \\
\hline Single & 1 & & & \\
\hline Educational level & & & & \\
\hline Tertiary & 1.663 & 0.666 & 0.166 & 16.668 \\
\hline Secondary completed & 1.497 & 0.730 & 0.151 & 14.855 \\
\hline Primary completed & 1 & & & \\
\hline Caesarean Section & & & & \\
\hline Yes & 0.523 & $0.007 *$ & 0.328 & 0.836 \\
\hline No & 1 & & & \\
\hline Booking GA in group & \multicolumn{5}{|l|}{} \\
\hline Un-booked & 6.712 & $<0.001 *$ & 3.144 & 14.327 \\
\hline$\leq 13$ weeks & 0.460 & 0.327 & 0.097 & 2.174 \\
\hline $14-28$ weeks & 1.213 & 0.606 & 1.213 & 0.583 \\
\hline$\geq 28$ weeks & 1 & & & \\
\hline
\end{tabular}


Delivering through caesarean section and gestational age at booking predicted preterm birth. Un-booked mothers have about 7 times odds of having PTB when compared to those that booked at $\geq 28$ week's gestation.

\section{DISCUSSIONS}

The prevalence of PTB in the present study was $12.2 \%$ (122 per 1000 births). This is high considering the fact that PTB is associated with most of the pregnancy-related mortality with its short and long-term disabilities. ${ }^{[18]}$ A similar study in a tertiary health facility also reported a similar prevalence of $12.0 \%$. ${ }^{[19]}$ Both studies were conducted in tertiary health facilities with similar characteristics and that can explain the similarity. Other studies however, reported lower findings in Nigeria $(8.5 \%),{ }^{[20]}$ Italy $(7.8 \%){ }^{[21]}$ and Abu Dhabi UAE $(6.3 \%)$. ${ }^{[22]}$ Moreover, the prevalence in the present study was lower than the WHO 'Born Too Soon" report for Nigeria which estimated PTB to be $15 \%$. ${ }^{\text {[23] }}$ Better and supervised ante-natal services in the present study site may explain the difference.

The differences in prevalence rates could also be explained by the nature of the studies, for instance, delivery at tertiary health facilities may be associated with high preterm births due to dealing with complicated pregnancies and referral from other centres, unlike some studies that are community-based. ${ }^{[24,25]}$ Another study from Nigeria also reported a higher prevalence of 16.9\%. ${ }^{[26]}$ The higher prevalence in this study may be due to the fact that they included multiple gestation in their study and included data from the neonatal intensive unit which may include pre terms that were delivered outside the hospital but were referred to the tertiary health facility for expert care.

Our study did not find any statistically significant association between extreme maternal age and PTB. However other studies have documented that extreme maternal age is associated with PTB. ${ }^{[5,27]}$
The difference may be explained by the special care given to this group of mothers in the tertiary health facility knowing that they are high risk pregnancies.

Also there was no statistically significant association between being single and PTB in our study though some other studies have reported such association. ${ }^{[7,9]}$ The socio-demographic characteristics of the women that delivered at the hospital may explain the difference.

Our study found out that delivery through Caesarean Section (C/S) was associated with PTB. About $16.3 \%$ of babies delivered through $\mathrm{C} / \mathrm{S}$ were PTB. This may be due to the fact that mothers who deliver through caesarean section have other pregnancy complications that may be an indication for the caesarean section. This was corroborated by other studies from $\mathrm{UAE}^{[22]}$ and Brazil. ${ }^{[28]}$

Booking status of the mothers predicted PTB as un-booked mothers had about 7 times odds of PTB when compared to the booked mothers. Other studies from Nigeria [29] and United Kingdom [30] corroborated the finding.

Lack of booking and poor prenatal care has been reported to negatively affect pregnancy outcome, such as increased maternal mortality, complicated maternal emergency, and perinatal mortality. [31] Early identification of risk factors in pregnancy is an essential component of good obstetric care and early interventions may be effective in mitigating against the risk of PTB. Prevention of PTB is a public health challenge that aims to reduce the infant and childhood morbidity and mortality. ${ }^{[32]}$

\section{CONCLUSION}

The prevalence of PTB is still high in Nigeria. Booking status of the mother and $\mathrm{C} / \mathrm{S}$ delivery were found to be strongly associated with PTB. Strategies should be put in place to educate prospective mothers on the importance of early booking and dangers of late booking or not booking at all. 


\section{Limitations}

There might have been an underestimation of the prevalence of PTB as the study excluded multiple gestations which is known to result in PTB most times. There might also have been an over estimation of preterm delivery as the institution is a referral center and thus handles complicated cases from peripheral hospitals.

\section{Acknowledgement: None}

\section{Conflict of Interest: None}

\section{Source of Funding: None}

\section{Ethical Approval: Approved}

\section{REFERENCES}

1. Liu L, Oza S, Hogan D et al. Global, regional, and national causes of under-5 mortality in 2000-2015: An updated systematic analysis with implications for the Sustainable Development Goals. Lancet. 2016; 388: 3027-3035.

2. World Health Organization. W.H.O. Recommendations on Interventions to Improve Preterm Birth Outcomes. WHO: Geneva, Switzerland. 2015.

3. Chawanpaiboon S, Vogel JP, Moller AB et al. Global, regional, and national estimates of levels of preterm birth in 2014: A systematic review and modelling analysis. Lancet Glob. Health. 2019; 7: 37-46.

4. Blencowe H, Cousens S, Oestergaard MZ et al. National, regional, and worldwide estimates of preterm birth rates in the year 2010 with time trends since 1990 for selected countries: a systematic analysis and implications. The Lancet. 2012; 379 (9832): 2162-2172.

5. Wagura P, Wasunna A, Laving A et al. Prevalence and factors associated with preterm birth at kenyatta national hospital. BMC Pregnancy Childbirth. 2018; 18: 107. https://doi.org/10.1186/s12884-018-1740-2.

6. Lasiuk GC, Comeau T, Newburn-Cook C. Unexpected: an interpretive description of parental traumas' associated with preterm birth. BMC Pregnancy Childbirth. 2013; 13(Suppl 1): $\quad$ S13;
http://dx.doi.org/10.1186/1471-2393-13-S1S13.

7. Zhang $\mathrm{Y}$, Liu $\mathrm{X}, \mathrm{Gao} \mathrm{S}$ et al. Risk factors for preterm birth in five maternal and Child Health hospitals in Beijing. PLoS One. 2012; 7(12): e52780.

8. Chang HH, Larson J, Blencowe $\mathrm{H}$ et al. Preventing preterm births: trends and potential reductions with current interventions in 39 very high human development index countries. Lancet. 2013; 381(9862):

223-234.

http://dx.doi.org/10.1016/S01406736(12)61856-X.

9. Ngowa JDK, Jean DK, Ngassam A et al. Pregnancy outcome at advanced maternal age in a group of African women in two teaching hospitals in Younde, Cameroon. Pan Afr Med J. 2013; 14: 134. Doi:10.11604/pamj.2013.14.134.2315

10. Zhang Q, Cande VA, Li Zhu et al. Maternal anaemia and preterm birth: a prospective cohort study. Int J Epidemiol. 2009; 38(5): 1380-1389 http://dx.doi.org/10.1093/ije/dyp243.

11. Alijahan R, Hazrati S, Mirzarahimi M et al. Prevalence and risk factors associated with preterm birth in Ardabil, Iran. Iran J Reprod Med. 2014; 12: 47-56.

12. Mahande MJ, Daltveit AK, Obure $\mathrm{J}$ et al. Recurrence of preterm birth and perinatal mortality in northern Tanzania: registrybased cohort study. Trop Med Int Health. 2013; 18(8): 962-967.

13. Menon R, Dunlop AL, Kramer MR et al. An overview of racial disparities in preterm birth rates: caused by infection or inflammatory response? Acta Obstet Gynecol Scand. 2011; 90(12), 1325-31, https://doi.org/10.1111/j.16000412.2011.01135.x.

14. Lawn JE, Kerber K, Enweronu-Laryea $\mathrm{C}$ et al. 3.6 million neonatal deaths-what is progressing and what is not? Semin Perinatol. 2010; 34(6): 371-86. https://doi.org/10.1053/j.semperi.2010.09.01 1.

15. Howson CP, Kinney MV, McDougall L et al. Born too soon: preterm birth matters. Reprod Health. 2013; 10(Suppl 1), S1, https://doi.org/10.1186/1742-4755-10-S1-S.

16. Bayman E, Drake AJ, Piyasena C. Prematurity and programming of cardiovascular disease risk: a future challenge for public health?. Arch Dis Child 
Fetal Neonatal Ed. 2014; 99(6): F510-4. https://doi.org/10.1136/archdischild-2014306742.

17. Steer P. The epidemiology of preterm labour. BJOG. 2005; 112(Suppl 1): 1-3. https://doi.org/10.1111/j.14710528.2005.00575.x.

18. Mathews TJ, MacDorman MF. Infant mortality statistics from the 2006 period linked birth/infant death data set. Natl Vital Stat Rep. 2010;58:1-31

19. Mokuolu OA, Suleiman BM, Adesiyun OO et al. Prevalence and determinants of preterm deliveries in the University of Ilorin Teaching Hospital, Ilorin, Nigeria. Pediatr Rep. 2010; (1)2:e3.

20. Etuk SJ, Etuk IS, Oyo-Ita AE. Factors influencing the incidence of pre-term birth in Calabar, Nigeria. Niger J Physiol Sci. 2005; 20(1-2): 63-68.

21. Granese R, Gitto E, D'Angelo G et al., Preterm birth: seven-year retrospective study in a single centre population. Italian Journal of Pediatrics. 2019; 45:45 https://doi.org/10.1186/s13052-019-0643-9

22. Taha Z, Hassan AA, Ludmilla WikkelingScott $L$ et al. Factors Associated with Preterm Birth and Low Birth Weight in Abu Dhabi, the United Arab Emirates. Int. J. Environ. Res. Public Health. 2020; 17: 1382. doi:10.3390/ijerph17041382

23. Blencowe H, Cousens S, Chou D et al. Born Too Soon: The global epidemiology of 15 million preterm births. Reprod Health. 2013; 10(Suppl 1):S2.

24. Hassan AA, Abubaker MS, Radi EA et al. Education, prenatal care, and poor perinatal outcome in Khartoum, Sudan. Int. J. Gynaecol. Obstet. 2009; 105: 66-67.

25. Zini ME, Omo-Aghoja LO. Clinical and socio-demographic correlates of preterm deliveries in two tertiary hospitals in southern Nigeria. Ghana Med. J. 2019; 53: $20-28$
26. Iyoke CA, Lawani OL, Ezugwu EC et al. Prevalence and perinatal mortality associated with preterm births in a tertiary medical center in South East Nigeria. International Journal of Women's Health. 2014:6: $\quad 881-888 . \quad$ DOI: 10.2147/IJWH.S72229

27. Islam MM, Bakheit CS. Advanced Maternal Age and Risks for Adverse Pregnancy Outcomes: A Population-Based Study in Oman. Health Care Women Int. 2015; 36: 1081-1103.

28. Barros FC, Rabello Neto DL, Villar J et al. Caesarean sections and the prevalence of preterm and early-term births in Brazil: Secondary analyses of national birth registration. BMJ Open. 2018; 8: e021538.

29. Butali A, Ezeaka C, Ekhaguere $O$ et al. Characteristics and risk factors of preterm births in a tertiary center in Lagos, Nigeria. Pan African Medical Journal. 2016; 24:1 doi:10.11604/pamj.2016.24.1.8382

30. Tucker T, Ogutu D, Yoong W et al. Nauta $\mathrm{M}$ et al. The unbooked mother: a cohort study of maternal and fetal outcomes in a North London Hospital. Arch Gynecol Obstet. 2010 Apr; 281(4):613-6.

31. Mokuolu AO, Abdul IF, Adesiyun O. Maternal factors associated with early spontaneous singleton preterm delivery in Nigeria. Trop J Obstet Gynaecol. 2002; 19:32-35.

32. Varol F, Er N, S ut N et al. A local study on ante natal features of preterm births at 26-32 versus 33-36 weeks of pregnancy. Gynecology Obstetrics \& Reproductive Medicine. 2018; 24(1): 1-6.

How to cite this article: Nwoga HO, Ajuba MO, Igweagu CP. Born too soon; implications in a tertiary health facility in Enugu state Nigeria. Int $J$ Health Sci Res. 2021; 11(6): 190-196. DOI: https://doi.org/10.52403/ijhsr.20210630 